\title{
Unlocking Founding Team Prior Shared Experience: A Transactive Memory System Perspective
}

\begin{abstract}
Although new ventures are often started by founders with prior shared experience, which has been shown to benefit new venture performance, the mechanisms underlying this effect remain under-examined. It therefore becomes challenging to exploit this entrepreneurial resource in practice. Drawing insights from the team familiarity and cognition literatures, I posit that the prior shared experience effect is partially mediated by a team-level cognitive process - transactive memory system that enables founding teams to effectively and efficiently integrate their members' expertise and skills. Two team-level factors — task similarity and intra-team trust further strengthen the effects of transactive memory systems because they provide golden opportunities and strong motivation for team members to utilize their transactive memory systems. Analyses using survey data collected from approximately 100 start-ups in four regions of China largely support these hypotheses. The theoretical and practical implications of these results are discussed.
\end{abstract}

Key Words: prior shared experience, transactive memory system, new venture performance. 


\section{Introduction}

Founders often have shared working experience prior to the creation of new ventures. For example, Google's two founders had worked together at Stanford University for several years before starting the well-known company. Baoqi Agency, a Chinese marketing information service provider, was also founded by three employees who had worked together for two years before starting their own company. Both cases and numerous other examples suggest that founding team prior shared experience is indeed ubiquitous. In this study I define prior shared experience as the shared working experience among founders prior to the creation of new ventures. Early studies have shown that prior shared experience constitutes a key entrepreneurial resource that founding teams can leverage and hence is positively correlated with new venture performance (Eisenhardt and Schoonhoven, 1990; Kor, 2003; Roure and Maidique, 1986). Nevertheless, the microfoundations of the prior shared experience effect are neither well understood nor carefully examined with few exceptions (Beckman, 2006; Harrison, Mohammed, McGrath, Florey and Vanderstoep, 2003; Zheng, DeVaughn and Zellmer-Bruhn, 2010). Without a clear understanding of the processes underlying the prior shared experience effect and the contingencies surrounding the causal paths from prior shared experience to new venture performance, it becomes challenging to assess the prior shared experience effect and exploit this valuable entrepreneurial resource in practice (Foss, 2010).

The deficiencies identified above are related to two streams of research in the entrepreneurship field. The first examines the impact of entrepreneurs' pre-founding experiences on new venture performance. This stream of research primarily focuses on the relationships between certain types of pre-founding experiences (e.g. industry experience and/or start-up experience) and new venture performance (Cooper, Gimeno-Gascon and Woo, 1994; Delmar and Shane, 2006; Klepper, 2001). Although this literature has accumulated a considerable amount of 
empirical evidence, it is still seeking more accurate accounts of how pre-founding experiences influence new venture performance beyond the basic human capital explanation. As leading entrepreneurship scholars (Gilbert, McDougall and Audretsch, 2006: p. 941) pointed out, "Expanding our knowledge of experiences beyond those relating to prior start-up or industry experience will greatly enhance our understanding of how prior experiences influence new venture growth."

Another relevant literature is the entrepreneurial cognition research that adopts a cognitive perspective in investigating entrepreneurial issues (Baron and Ward, 2004; Mitchell, Busenitz, Bird, Marie Gaglio, McMullen, Morse and Smith, 2007). Entrepreneurial cognitions are defined as knowledge structures that people use to make assessments, judgments, or decisions involving opportunity evaluation, venture creation, and growth (Mitchell, Busenitz, Lant, McDougall, Morse and Smith, 2002). Entrepreneurs have been found to think differently from managers (Busenitz and Barney, 1997), follow certain cognitive styles (Dutta and Thornhill, 2008), and develop metacognition during the entrepreneurial processes (Haynie, Shepherd, Mosakowski and Earley, 2010). Recent development suggests that the entrepreneurial cognition literature will benefit by shifting its focus from individual- to team-level cognition, since the locus of entrepreneurial activity often resides not in one person but in many acting as a team (Chowdhury, 2005; Harper, 2008). For example, Blatt (2009) theorized that founding teams can adopt communal schema-a team-level cognitive structure - to deal with challenges arising from start-up process. Because heterogeneity exists for team-level cognitive structures, the entrepreneurial cognition research holds the potential to explain the micro-foundations of certain entrepreneurial resources.

The purpose of this study is to extend the line of inquiry in the two literatures above by examining the effect of prior shared experience on new venture performance from a team cognition perspective. The key premise is that new venture performance hinges on the efficient and effective 
integration of founders' expertise, skills, and other resources (Grant, 1996; Kogut and Zander, 1992). Building on this premise and drawing insights from the team familiarity and cognition literatures, I propose that a transactive memory system as a team-level cognitive process can effectively and efficiently integrate knowledge and skills among founding team members, thus partially mediating the effect of prior shared experience on new venture performance. I further propose that task similarity and intra-team trust positively moderate the effects of transactive memory systems on new venture performance because they provide golden opportunities and strong motivation for team members to utilize transactive memory systems.

This study makes several contributions. First, it proposes a transactive memory system explanation as the micro-foundations of one key entrepreneurial resource - prior shared experience. The results suggest that transactive memory systems serve as an important mediator for prior shared experience to take effect. Second, this study contributes to the entrepreneurial cognition research literature, particularly at team level. As leading entrepreneurship scholars lamented, “...few studies in this field explored the link between team cognition and entrepreneurial performance" (Grégoire, Corbett and McMullen, 2011: 1462). By taking a team cognitive perspective this study helps the knowledge accumulation regarding how team-level cognitive factors impact new venture performance. Third, this study also informs the transactive memory system literature. The theorizing and results on task similarity and intra-team trust as moderators suggest that the future studies need to consider the contingencies surrounding the effects of transactive memory systems, especially how social factors such as trust shape the effects of transactive memory systems. Lastly, this study also contributes to entrepreneurial practices. The results suggest that founding teams need to understand precisely how prior shared experience takes effect so that they can best exploit this valuable resource. Another lesson for practitioners is to 
reevaluate the role of intra-team trust because the results of this study reveal that intra-team trust contributes little to new venture performance without transactive memory systems in place.

The paper is organized as follows. First, I introduce the prior shared experience phenomenon and relevant literatures. I then develop three testable hypotheses by weaving together insights from the team familiarity and cognition literatures. The method section describes how I designed survey items, collected sample start-ups, and tested the proposed hypotheses. Finally, I present the empirical results, and discuss the theoretical and practical implications.

\section{Theory and Hypotheses}

\subsection{Prior Shared Experience and New Venture Performance}

\subsubsection{The Team Familiarity Literature}

I draw insights primarily from two related literatures to extend the research on the prior shared experience phenomenon - team familiarity and transaction memory systems. A sizeable literature on team familiarity has shown that familiarity among working team members is generally beneficial due to knowing specific details of member's unique knowledge, skills, and personal characteristics (Gruenfeld, Mannix, Williams and Neale, 1996; Katz, 1982). The early work on familiarity among coal mine workers concluded that teams with familiar members on average produce more and incur fewer accidents because of a decrease in coordination losses (Goodman and Garber, 1988; Goodman and Leyden, 1991). Recent work on familiarity among software team members showed that team familiarity in terms of shared working experience has a positive impact on software project performance, particularly when members are geographically dispersed because team familiarity helps offset communication and coordination issues (Espinosa, Slaughter, Kraut and Herbsleb, 2007). Kor (2003) hypothesized that team familiarity in terms of shared managerial tenure represents a valuable and hard-to-imitate resource for technology companies, but she found no significant impact of team familiarity on firm performance in a sample of public medical device 
companies. In fact, some studies have suggested that team familiarity may hurt team performance due to information insulation or groupthink (Gruenfeld et al., 1996). Team members who are familiar with one another may spend more time on social interactions and divert energy from team goals (Zenger and Lawrence, 1989).

The above discussion regarding team familiarity is relevant not only for functional teams in established firms, but also for voluntary teams such as founding teams of new ventures. On the positive side, early entrepreneurship studies on founding team prior shared experience made similar arguments that founding teams with familiar members perform better because of improved coordination, strong team cohesion, and/or enhanced intra-team trust. Roure and Maidique (1986) discovered that prior shared experience is associated with new venture success in a sample of venture capital funded high tech start-ups. However, recent work has suggested that founding team familiarity may not always be beneficial. Prior shared affiliations among founders are found to benefit new ventures in terms of speeding up first shipment of products, but not to contribute to new venture growth partly due to limited access to external resources (Beckman, 2006; Beckman, Burton and O'Reilly, 2007).

One approach to reconcile the seemingly competing arguments and mixed findings is to examine the timing of team familiarity. Harrison et al. (2003) proposed a temporal view of team familiarity contending that team familiarity is particularly beneficial during team formation stage when uncertainty is high. Their longitudinal experiments showed that teams composed of friends or acquaintances perform significantly better than those composed of strangers, but this gap shrinks over time. This temporal view of team familiarity is more relevant to this study because launching and growing a new venture is quite uncertain by any measures. I therefore take a parallel logic arguing that prior shared experience is beneficial for new venture performance.

\subsubsection{The Transactive Memory System Literature}


The transactive memory system literature provides another explanation for how and why prior shared experience positively impacts new venture performance. A transactive memory system is defined as the sum of the individual knowledge and shared understanding of the location of expertise among team members (Lewis, 2003; Moreland and Myaskovsky, 2000). It is commonly referred as "who knows what" or directory knowledge. The concept of transactive memory was conceived by Wenger (1987) in his discovery that married couples perform recall tasks better than pairs of strangers. He attributed this effect to the memory structure developed by couples from their shared experience. Subsequent research extended the notion of transactive memory to transactive memory systems by applying the concept from dyadic relationships (e.g. couples) to working teams such as sales, crisis handling, and top management teams (Austin, 2003; Majchrzak, Jarvenpaa and Hollingshead, 2007; Rau, 2005).

Prior studies have shown that transactive memory systems can be fostered in both experimental and field environments via shared working experience (Lewis, 2004; Moreland and Argote, 2003). In this study I propose that shared working experience leads to the development of transactive memory systems. Unlike team members who develop short-term transactive memory systems by observing each other in experimental environments, working teams in real organizations develop more robust and natural transactive memory systems via multiple communication channels such as meetings, emails, phone calls, and informal conversations (Hollingshead, 1998; Walsh, 1995). Founding team members who have prior shared experience could develop accurate and dynamic understanding of each member's expertise and skills through the multitude of communication and interaction (Beckman, 2006). Anecdotal evidence also supports this transactive memory system development possibility, especially for founding teams who are often engaged in more intensive communication than working teams in established firms (Lusk and Harrison, 2002). 
Teams with established transactive memory systems generally perform better than teams with less developed transactive memory systems for the following reasons. First, transactive memory systems enable team members to assimilate and transfer information in a more organized manner, reducing the cognitive resource demand for the entire team. Early experimental studies showed that both married couples who have developed natural transactive memory systems and pairs of strangers who are trained to develop artificial transactive memory systems can learn and recall more words than pairs of strangers (Hollingshead, 1998; Wegner, 1987). This advantage is particularly beneficial for start-ups that must deal with tremendous information in-flow. More importantly, transactive memory systems allow teams to accurately assign tasks to members with relevant skills or expertise, thereby increasing the efficiency and effectiveness of team work. Evidence from experimental studies, computer simulations, and field work has shown that teams with established transactive memory systems perform better in tasks such as radio assembly, software projects, and functional teamwork (Liang, Moreland and Argote, 1995; Ren, Carley and Argote, 2006; Zhang, Hempel, Han and Tjosvold, 2007). Compared to the team familiarity literature, the transactive memory system theory offers clear causal arguments (Liang et al., 1995; Moreland and Myaskovsky, 2000). The transactive memory system literature therefore differs from the team familiarity literature that proposes a variety of factors as the causal drivers including cohesion, trust and social identity (Berman, Down and Hill, 2002; Eisenhardt and Schoonhoven, 1990; Reagans, Argote and Brooks, 2005).

In an entrepreneurial context, founding teams may benefit from the transactive memory systems developed from prior shared experience. For example, Baoqi Agency, was established by three founders who had worked together as region manager, marketing director, and graphic designer respectively. Their prior shared experience provided a nuanced understanding of each other's expertise, skills, and social connections. This understanding facilitated decision making and 
enabled the founding team to take coordinated actions dealing with a variety of issues related to entrepreneurial activities. I therefore anticipate that after accounting for other factors, a founding team's transactive memory system partially mediates the effect of prior shared experience on new venture performance.

\section{H1: The impact of prior shared experience on new venture performance is partially mediated by a founding team's transactive memory system.}

I hypothesize above that the prior shared experience effect is partially mediated by transactive memory systems derived from prior shared experience because transactive memory systems represent a key entrepreneurial resource or competence in terms of integrating founders' knowledge, skills and other resources. Nonetheless, scholars have argued that learning will be most effective when ability to learn, opportunity to learn and motivation to learn coexist (Argote, McEvily and Reagans, 2003). Although transactive memory systems represent a critical ability for founding teams to exploit existing knowledge and assimilate new information, the right opportunities and motivation need to be present to boost the value of this ability. Because task similarity between prior organizations and new ventures provides golden opportunities for founding teams to integrate members' knowledge and skills and intra-team trust provides the necessary incentives for founding teams to share and create knowledge among members, I propose that task similarity and intra-team trust will positively moderate the relationship between transactive memory systems and new venture performance.

\subsection{Task Similarity}

Management scholars have long been arguing that teams and organizations develop mental representations or cognitive structures to cope with their task environments (Walsh, 1995).

Different task environments specify different means-ends relationships and hence demand different cognitive structures. The fit between task environments and cognitive structures plays a critical 
role to achieve superior performance because mental representations will guide behaviors such as allocations of resources and strategic decision making that have profound impact on performance (Milliken, 1987; Sutcliffe and Huber, 1998). Task similarity refers to the perceptional difference between two task environments. The team familiarity literature suggests that task similarity and team familiarity combined should have stronger impact on team performance than either alone. Working teams seem to have higher productivity when they are composed of familiar members and work in similar task environments. The productivity increase is attributed to the desirable match between team member interactions and people-environment interactions (Espinosa et al., 2007; Goodman and Leyden, 1991). In contrast, when managers hold old mental representations but the surrounding task environments have changed substantially, they could make erroneous decisions that lead to inferior performance or even disastrous outcomes. Tripsas and Gavetti (2000) documented a vivid account of how the top management team of Polaroid stuck to its instant imaging business model and missed out the emerging digital photo opportunity.

Researchers have argued that transactive memory systems should be viewed in specific task environments (Austin, 2003; Brandon and Hollingshead, 2004). A task environment provides meaningful cues for team members to assign, store information, and trigger retrieval from the appropriate members. Depending on the similarity between the past and current task environments, part of the transactive memory system or "who knows what" knowledge will be rendered invalid in the current task environment. Familiar teams therefore may not be able to take advantage of transactive memory systems in new task environments. In a series of experimental studies, Littlepage et al. (1997) noticed that team experience contributes to the recognition of expertise among members only when similarity exists between tasks. Therefore, team experience does not necessarily contribute to the "who knows what" knowledge if tasks differ. Similarly, Schilling et al. (2003) found that related task variation enhances learning rates more than unrelated task variation 
partly because mental representations are similar in related tasks. Together these studies suggest that the utility of transactive memory systems will be enhanced in similar task environments but suppressed in dissimilar task environments.

In entrepreneurial settings, a new venture is often a new task environment that demands accurate mental representations for founders to effectively process information and make appropriate decisions. Thus similarity between pre-venture experience and the current venture is beneficial for founders to transfer their prior working experience to new ventures (Cooper et al., 1994). Subsequent studies extended this logic and found that task similarity between prior working experience and the current venture positively moderates the effect of pre-ownership experience on new venture performance (Chandler, 1996; Zheng et al., 2010). Anecdotal evidence also suggests that entrepreneurs need to adjust their cognitive structures when key dimensions of task environments change, especially for those executives who make career transitions from established firms to start-ups within the same industry (Deogun, 1996; Gartner, Starr and Bhat, 1999). I therefore conjecture that founding teams can better leverage transactive memory systems developed from prior shared experience if they start new ventures in similar task environments such as related industries, than if they start new ventures in dissimilar task environments that render their transactive memory systems less relevant.

Prior studies primarily focused on transferring relevant knowledge or skills directly to a new task environment. For example, some studies have found that founders can apply the knowledge inherited from prior employers to new ventures (Agarwal, Echambadi, Franco and Sarkar, 2004; Klepper, 2001). My moderating hypothesis, however, highlights team-level coordination and knowledge integration. I therefore do not rule out the possibility that each founder can apply prior working experience individually, but I emphasize the moderating role of 
task similarity on shaping the effect of team-level knowledge integration and coordination. Taken together, I hypothesize:

\section{H2: The positive relationship between a founding team's transactive memory system and new venture performance will become stronger as task similarity increases.}

\subsection{Intra-Team Trust}

A great number of scholars have argued that trust is an important factor in organization life. Trust can be defined in various ways; one common definition is the willingness to accept vulnerability based on positive expectations regarding another's intentions or behaviors (Dirks and Ferrin, 2001; McEvily, Perrone and Zaheer, 2003). Since this study concerns team-level trust, I further define intra-team trust as the shared perception of trust among team members (De Jong and Elfring, 2010; Simons and Peterson, 2000). While the majority of studies on trust examine the antecedents and consequences of trust, I argue that intra-team trust serves as a key moderator that influences the relationship between prior shared experience and new venture performance.

First, intra-team trust increases the awareness of expertise among team members and thus boosts the effects of transactive memory systems on team performance. The conventional metaphor for transactive memory systems is distributed computer memories. The underlying assumption is that the awareness of members' expertise and skills is clear-cut: either knowing or not knowing. However, recent studies have discovered that expertise awareness may be situated within the social exchange context such that knowing or not knowing is shaped by social relationships, particularly by trust among members (Casciaro and Lobo, 2008). Workers are more likely to identify expertise from less competent members whom they trust than from more competent members they don't trust (Yuan, Carboni and Ehrlich, 2010). Team members who perceive the team as a trustful environment are willing to disclose private information; this enables 
other members to accurately assess members' true expertise and assign information or tasks to the most appropriate members (Gruenfeld et al., 1996).

Intra-team trust also encourages cognitive conflict among team members. It is commonly believed that members with mutual trust are willing to not only disclose private information but also confront each other without worrying about negative consequences. Edmondson (1999) found that team members are more likely to engage in learning behaviors such as challenging one another's opinions in a psychologically safe environment. De Jong and Elfring (2010) argued that intra-team trust encourages teams to reflect on potential or actual performance problems and therefore increase team reflexivity. Intra-team trust among members enhances the impact of transactive memory systems on team performance such that teams armed with both transactive memory systems and intra-team trust can increase the entire team's knowledge stock (Henry, Strickland, Yorges and Ladd, 1996) and better exploit this increased knowledge. Conversely, teams lacking intra-team trust lose opportunities to furnish their knowledge stock, and transactive memory systems therefore only allow them to assign information or tasks based on factors such as prior experience or job titles (Bunderson, 2003).

Intra-team trust improves coordination among team members, since its development from social or working interactions reduces the emotional conflict among members (McEvily et al., 2003). Intra-team trust therefore prevents members from second-guessing other members' intentions and hence increases operational efficiency. Intra-team trust also enhances the credibility of members' expertise when assigning tasks. Rau (2005) found that transactive memory systems become more influential when top bank executives exhibit high level intra-team trust. She attributed this moderating effect to a higher awareness of expertise among team members as well as retrieving more accurate information from team members. Applying the same logics to an 
entrepreneurial context, founding teams with high levels of intra-team trust and transactive memory systems will benefit from the combination of both more than from either alone.

Similar to H2, I acknowledge the possibility of the direct effect of intra-team trust. Indeed, the majority of studies on trust have examined the main effects of trust on team behaviors and performance in both established (De Jong and Elfring, 2010) and entrepreneurial firms (Blatt, 2009). Because I consider transactive memory system as the central construct and its mediating effect as the key causal path, I acknowledge the direct impact of intra-team trust but examine primarily the moderating role of intra-team trust in this study. In sum, intra-team trust increases the awareness of members' expertise, the precision of transactive memory systems, and the smoothness of coordination among members. I therefore hypothesize:

H3: The positive relationship between a founding team's transactive memory system and new venture performance will become stronger as intra-team trust increases.

Figure 1 summarizes the theory development and presents the overall conceptual model.

\section{[Insert Figure 1 about Here]}

\section{Method}

\subsection{Sample}

China is experiencing unprecedented economic growth, and is therefore becoming a fertile ground for entrepreneurship. I collected survey data from start-ups founded between 2007 and 2008 in four geographic regions of China that represent different levels of entrepreneurial activities (Global Entrepreneurship Monitor 2008: The China Report). Surveys were mailed to 400 randomly selected start-ups and asking the key founders to respond. Target start-ups were identified from local business directories; their existence and correspondence information were confirmed and retrieved from local regulatory agencies. A pilot survey was sent to 30 executive MBA students with founding experience in these four regions. Based on the pilot survey results and consequent 
interviews, I reworded some survey items and added several items to improve readability. A letter was attached to the survey indicating that the purpose of the survey was for academic research only and participants would be qualified for free consulting from the researchers in exchange for responding. ${ }^{1}$ Moreover, the survey promised to protect the identity of each founder and report only statistics. Key survey items included founders' demographic characteristics, career histories including the three most recent jobs, whether or not each had worked with other founders at these recent jobs, transactive memory system items, task similarity items, intra-team trust items, and other related items. All survey items were prepared in English and then translated into Chinese by two researchers who are proficient in both languages. The Chinese version was back translated into English by two independent translators. The two researchers discussed any conflicts arising from the translation and back translation processes until they reached an agreement. The tested Chinese version survey items were then sent to the informants.

In total 142 start-ups responded, resulting in an approximately 36 percent return rate. I performed a one-way analysis of variance to test for non-response bias. The results indicated no significant differences between responding and non-responding firms with respect to size, location, and industry. For example, the average firm size of responding firms is 61 employees (S.D.=75), while the average size of non-responding ones is 73 (S.D.=89). The t statistic is 1.22 and not significant ( $p>$.2). I removed nine firms due to either missing or inaccurate information. Another 35 firms were removed as having either a single founder or fewer than $50 \%$ of the founders responded. I adopted this 50\% team-level response rate to construct reliable team-level variables (De Jong and Elfring, 2010; Faraj and Sproull, 2000). The procedure yielded 98 start-ups with complete data for analyses. The average founding team size is 3.24 . The sample start-ups covered industries such as business services, information technology, and medical devices.

\footnotetext{
${ }^{1}$ The pilot survey and interviews revealed that entrepreneurs considered monetary incentives as meaningless. Instead, they deemed free consulting as more attractive.
} 


\subsection{Dependent Variable}

New Venture Growth. Since the sample start-ups spread across various industries and were still in early stages, a universal profit-based performance variable is not feasible. I therefore adopted a self-reported approach. Following the new venture growth literature, three survey items asked for each firm's sales, employee, and market share growth on a six-point Likert scale (Chandler, 1996; Eisenhardt and Schoonhoven, 1990). For example, one item asked whether the focal firm's annual sales did not increase (coded as 1), increased between 1 and 10\% (coded as 2), $11 \%$ and $30 \%$ (coded as 3), $31 \%$ and $50 \%$ (coded as 4 ), $51 \%$ and $100 \%$ (coded as 5), or above $100 \%$ (coded as 6). To ensure the accuracy of this self-reported performance data, I obtained sales and employee numbers from databases such as the China Industrial Survey for approximately 12 start-ups. In addition, I also interviewed the founders of five other start-ups. Both checks confirmed the accuracy of the self-reported data. The three growth items exhibit high correlations and the coefficient alpha is .83 , exceeding the .70 threshold recommended by the methodology literature (Nunnally and Bernstein, 1994). I therefore combined them to construct a composite growth variable.

\subsection{Independent Variables}

Prior Shared Experience. I took two steps to construct the prior shared experience variable. First, I considered each pair of founders to have prior shared experience if they had worked together with another founder in a direct manner for at least one year in prior organizations using the founders' career records. ${ }^{2}$ I coded 1 for this dyadic connection and 0 otherwise. I then summed up all values (1s and $0 \mathrm{~s})$ and divided the sum by $\mathrm{N}^{*}(\mathrm{~N}-1) / 2$, or the total number of all possible dyadic connections. Mathematically the formula is $\sum \mathrm{D} i j /\left(\mathrm{N}^{*}(\mathrm{~N}-1) / 2\right)$, where $\mathrm{D} i j$ is an indicator variable showing whether or not founder $i$ and $j$ had shared working experience together before,

\footnotetext{
${ }^{2}$ This measurement of prior shared experience is therefore different from a common affiliation measurement where the members may or may not have direct interactions (Beckman, 2006).
} 
and $\mathrm{N}$ is the number of founders. This variable is a continuous one with a theoretical minimum of 0 (no prior shared experience) and maximum of 1 (complete prior shared experience), compatible with similar measures adopted by previous studies (Berman et al., 2002; Kor, 2003; Reagans et al., 2005; Zheng et al., 2010).

Transactive Memory System was measured using the established scale along three key dimensions: specialization, credibility, and coordination with five items for each dimension (Lewis, 2003). This scale has been widely adopted by prior studies utilizing the transactive memory system construct (Lewis, 2004; Rau, 2005; Yuan et al., 2010; Zhang et al., 2007). In this study founders were asked to respond to each item using a five-point Likert scale ranging from 1 (strongly disagree) to 5 (strongly agree). For example, one item on specialization stated, "each founder has specialized knowledge of some aspects about running a start-up.” The Cronbach's alpha coefficients for each dimension were $.79, .81$, and .83 respectively. Following the convention in the transactive memory system literature, I consolidated all items to form an overall transactive memory system variable (Austin, 2003; Lewis, Lange and Gillis, 2005; Liang et al., 1995; Zhang et al., 2007).

Task Similarity was measured by survey items asking founders how they perceived the current venture as differing from previous working experience. This scale was adapted from prior studies that have identified several key dimensions such as suppliers, customers, competitors, and technology as the defining characteristics of a task environment (Chandler, 1996; Cooper et al., 1994). However, from the pilot survey I found that Chinese entrepreneurs often considered the suppliers dimension as non-essential in decision making. I therefore dropped the suppliers dimension and added two additional considerations, financing and human resources. Each item is rated from 1 (very dissimilar) to 5 (very similar) using a five-point Likert scale. The Cronbach's 
alpha coefficient is .72. I then summed all items for each individual and aggregated all members' scores to construct a task similarity variable for the entire founding team (Chandler, 1996).

Intra-Team Trust was measured by a scale used in prior studies that defined intra-team trust similarly to this study (De Jong and Elfring, 2010; Simons and Peterson, 2000). The survey items were worded carefully to reflect the positive expectations of members. Specifically, I included five items asking whether or not the team members trusted each other on a five-point Likert basis from 1 (strongly disagree) to 5 (strongly agree). For example, one item stated, "I am confident that my team members will take my interests into account when making decisions." This variable exhibits a high level of internal consistency $(\alpha=.91)$. I also aggregated all items to form an overall intra-team trust variable.

I performed a confirmatory factor analysis (CFA) to assess both the convergent and discriminant validity of the key team-level constructs: transactive memory system, task similarity, and intra-team trust. The CFA yielded an acceptable fit for the data. Specifically, I examined three model fitness statistics suggested by prior studies (Bentler, 1990; Hoyle and Panter, 1995): the Comparative Fit Index (CFI=.92), Root Mean Square Error of Approximation (RMSEA=.06), and Standardized Root Mean Square Residual (SRMR=.06). Furthermore, the results indicated that alternative models (e.g. a two-factor model where transactive memory system and intra-team trust constituted a single latent variable) did not provide a better fit for the data. Table 1 presents factor loadings of all three explanatory variables from the CFA using three factors.

\section{[Insert Table 1 about Here]}

Since all three team-level explanatory variables (transactive memory system, task similarity, and intra-team trust) are constructed from the perceptional responses of more than one team member, inter-rater reliability should be assessed to justify aggregating individual scores to into team-level values. The $\mathrm{r}_{\mathrm{wg}}(\mathrm{j})$ values were between .76 and 1 for all items, indicating a sufficient 
level of within-team agreement (James, Demaree and Wolf, 1984). I also calculated intra-class correlation coefficients (Bliese and Halverson, 1998). The ICC (1) values ranged between .14 and .19, exceeding the generally accepted cutoff value of .12; the ICC (2) values were between .67 and .76, close to the threshold level of .7.

\subsection{Control Variables}

First, I created three region dummies to allow for geographic differences. In addition, the team diversity literature has shown that the demographic diversity of teams has a profound impact on team decisions and behaviors (Beckman et al., 2007; Chowdhury, 2005; Gibson and Vermeulen, 2003). Following the conventions of the team diversity literature, I created three diversity variables to capture the dispersion of age, gender, and education among founding team members. Age diversity was measured as the standard deviation of the founders' ages. Gender diversity and education diversity were measured using two Blau indices that treated each gender and education level (e.g. high school or college) as a distinct category (Harrison and Klein, 2007). The pilot survey and interviews revealed that founders with ethnic minority backgrounds might benefit from their unique identities either via certain governmental policies or special social networks. I therefore added a dummy variable, ethnic minority, indicating whether or not any founder was an ethnic minority (coded as 1 if yes and 0 otherwise). Founding teams with longer working experience may be able to make more informed decisions due to the expertise accumulated from their prior experience (Chandler, 1996). So I created another control—-total working experiencemeasured as the natural log of the total years of industry experience for all founders. This variable is a proxy of the total knowledge stock potentially exploitable by the founding teams. Finally, recent entrepreneurship work has recognized the importance of prior founding experience (Delmar and Shane, 2006). Founding teams with this experience may be able to manage the founding process better than teams without this experience. I therefore created another control, prior 
founding experience, measured as the number of founders who started any businesses prior to joining the focal start-up. Another control variable is ongoing shared experience or the shared working experience among founders following the establishment of the start-up (Zheng et al., 2010). I measured it in a similar manner to prior shared experience, using a unit of month rather than year. The rationale is that founding teams may develop transactive memory systems via ongoing operating experience in addition to prior shared experience.

\section{Analyses and Results}

\subsection{Analyses}

I employed a hierarchical ordinary least squares (OLS) estimation to test the hypotheses. Specifically, I followed the Baron and Kenny's (1986) recommendation to examine the mediating effect (H1). The first condition for claiming a mediation effect states that the independent variable should be significantly related to the dependent variable without the mediator. If the first condition is met, the next step is to ensure that the independent variable is significantly related to the mediator. The final condition is that when both the independent variable and mediator are included in the regression, the direct relationship between the independent variable and the dependent variable should be either less significant or become zero. Thus I entered prior shared experience first and then added transactive memory system. If the hypothesized mediating effect exists, the transactive memory system variable will absorb the effect of prior shared experience on new venture performance. Huber and White robust standard errors were used to compute the $t$ statistics.

\subsection{Results}

Table 2 presents the descriptive statistics and correlation coefficients among the key variables included in the analyses. On average the sample start-ups grew sales, firm sizes and market shares at 10 to 50 percent. Approximately 68 percent of the respondents were male and 20 percent of the respondents were of minority ethnicity. A typical profile of the sample founders is a 
male in his mid-30s with a college degree and five to ten years of working experience. The majority of correlation coefficients are within acceptable levels $(<.3)$. A formal VIF test shows that most values are less than 3.8 , below the conventional threshold value 10 which may raise multicollinearity concerns (Kleinbaum, Kupper, Muller and Nizam, 1988).

\section{[Insert Table 2 about Here]}

The results of the hierarchical OLS estimation are reported in Table 3. The control variables and prior shared experience were entered first in Model 1. When controlling for the effects of founders' prior working experience, prior founding experience, and other factors, prior shared experience demonstrated a positive and significant impact on new venture growth $(b=.53$, $\mathrm{p}<.05)$. However, when the transactive memory system variable was added in Model 2, the coefficient of prior shared experience became less significant $(b=.40, p<.1)$. Instead, the transactive memory system variable exhibited a positive and significant impact on new venture growth $(b=.42$, $\mathrm{p}<.05$ ). Moreover, a regression of transactive memory system on prior shared experience showed a positive and significant effect of prior shared experience on transactive memory $(b=3.05, p<.01)$. These results satisfy the three conditions necessary for declaring a mediating effect (Baron and Kenny, 1986). Together these results support $\mathrm{H} 1$ that the prior shared experience effect on new venture growth is partially mediated by a founding team's transactive memory system. Two interaction terms were entered both separately and collectively to test $\mathrm{H} 2$ and $\mathrm{H} 3$. As predicted, in Models 4, 5 and 6 (the full model) the coefficients of both interaction terms (transactive memory system*task similarity and transactive memory system*intra-team trust) were positive and but only marginally significant $(b=.33, p<.1 ; b=.32, p<.1)$ in the full model. H2 and H3 are therefore weakly supported. Surprisingly, intra-team trust exhibited a non-significant impact on new venture growth when entered without its interaction with transactive memory system. Figure 2 visually demonstrates the hypothesized moderating effects or the marginal effects of transactive memory 
system on new venture growth at one standard deviation above and below the means of the moderators — task similarity and intra-team trust (Cohen, Cohen, West and Aiken, 2003).

\section{[Insert Table 3 \& Figure 2 about Here]}

\subsection{Sensitivity Tests}

Since prior shared experience might correlate with other team-level factors such as team cohesion (Austin, 2003), I also examined a plausible hypothesis that team cohesion rather than transactive memory system mediates the prior shared experience effect on new venture performance. Team cohesion refers to an affective psychological state that reflects the shared commitment and attraction emerging from the experiences and interactions among team members (Beal, Cohen, Burke and McLendon, 2003). Team cohesion is an important indicator of the bond among team members, influencing the execution of subsequent teamwork processes and outcomes. Specifically, team cohesion was measured using six items as suggested by prior studies (Beal et al., 2003). Similar arguments can be made for intra-team trust, which may also serve as a mediator between prior shared experience and new venture performance. Yet both the reported results and the post hoc analyses found no support for these possibilities. The team cohesion variable did show a positive impact on new venture growth but was not significantly correlated with prior shared experience. Intra-team trust was indeed positively and significantly correlated with prior shared experience, but the mediating effect of intra-team trust was not significant.

I also experimented with an alternative measurement of prior shared experience that takes the length of shared experience into account. The formula is $\sum \mathrm{Dij}{ }^{*} \mathrm{LENGTHij} /(\mathrm{N} *(\mathrm{~N}-1) / 2)$, where Dij is a dummy indicating whether or not founder $i$ and $j$ had worked together before, LENGTHij is the number of years that founder $i$ and $j$ had worked together, and $\mathrm{N}$ is the number of founders (Zheng et al., 2010). I also tested the possibility of an inverted U-shaped relationship between prior shared experience and new venture performance because the mediation effect might arise from a 
model misspecification or an alternative view that proposes a curvilinear relationship between team familiarity and team performance (Berman et al., 2002; Katz, 1982). The squared term of prior shared experience had a non-significant regression coefficient, lending no support to the possibility of an inverted U-shaped relationship. Moreover, this alternative specification did not change the mediation effect of the transactive memory system variable.

Finally, I tested some other possible control variables such as founding team size and industry dummies. I found virtually no impact of founding team size on new venture growth, consistent with the findings in prior studies (Beckman, 2006; Delmar and Shane, 2006). When industry dummies were entered, they neither showed significant impacts nor improved the model fit. Past studies investigating small businesses in developing markets found similar results, perhaps due to the unstable industry dynamics in these emerging markets (Khavul, Pérez-Nordtvedt and Wood, 2010). To preserve simplicity and statistical power I opted to report results without these additional controls.

\section{Discussion}

\subsection{Discussion of Results}

Heterogeneity in terms of resource endowment has a profound impact on the success of new ventures (Bamford, Dean and McDougall, 2000). Prior shared experience among founders is considered as a key entrepreneurial resource for new ventures with limited financial and human capital (Eisenhardt and Schoonhoven, 1990; Kor, 2003). This study examines how transactive memory systems mediate the impact of prior shared experience on new venture performance. First and foremost, this study not only replicates the positive relationship between prior shared experience and new venture performance, but also reveals one specific causal path underlying the prior shared experience effect. Rather than speculating on several plausible mechanisms, I draw from two relevant literatures (team similarity and cognition) to argue how prior shared experience 
contributes to new venture performance via developing transactive memory systems among founders. Transactive memory systems enable founding teams to assimilate information, assign tasks, and coordinate more efficiently and effectively than teams without these cognitive structures. Furthermore, this study also proposes and tests the possibility that the effects of transactive memory systems on new venture performance are shaped by two team-level factors. The two moderators merit discussion. First, the positive effects of transactive memory systems on new venture performance are strengthened in similar task environments, highlighting the importance of opportunities when founding teams apply their transactive memory systems. Additionally, I examined how intra-team trust moderates the relationship between transactive memory systems and new venture performance. The results show that intra-team trust also boosts the impact of transactive memory systems on new venture performance by increasing information sharing, learning behaviors, and coordination among team members. Interestingly, although both task similarity and intra-team trust are positive moderators, they exhibit slightly different patterns if we examine these interactions from the moderators' perspective. Figure 2 shows that, when founding teams have low levels of transactive memory system, they appear to perform better in dissimilar task environments than in similar task environments. However, when founding teams have high levels of transactive memory system, this performance gap reverses its sign from positive to negative. This result implies that founding teams with less-developed transactive memory systems might explore information diversity better in a novel environment (Beckman, 2006). In contrast, regardless of whether transactive memory systems are high or low, founding teams with high levels of intra-team trust always outperform those with low levels of intra-team trust, suggesting that intra-team trust is indeed a valuable asset for founding teams.

One striking result is that intra-team trust alone contributes little to new venture performance. While further exploration is needed, my speculation is that intra-team trust might 
serve as a supporting factor rather than the primary driver for new venture performance (Dirks and Ferrin, 2001); without transactive memory systems in place intra-team trust contributes little to new venture performance. This possibility was manifested in several sample start-ups established by either family members or friends who had close social bonds, but did not necessarily have developed transactive memory systems. For instance, DH Medical Device Inc. (anonymous name) was founded by family members who worked in different organizations prior to the founding. Although the founding team demonstrated tremendous intra-team trust, the key founders confessed later that they did not actually know their brothers or nephews as much as they thought when it came to running real businesses.

\subsection{Contributions to Theory and Practice}

This study makes several contributions. First, it echoes the call for investigating the microfoundations of entrepreneurial resources (Foss, 2010; Gilbert et al., 2006). On the surface it appears that this study only replicates the previously discovered prior shared experience effect in a different setting. However, the conceptual framework of this research differs substantially from that of previous studies. The findings of this study suggest that the pre-founding experience literature could benefit from cross-fertilization by incorporating novel perspectives, especially a cognitive perspective (Grégoire et al., 2011). In fact, carefully adopting a cognitive perspective in entrepreneurship research may have the potential to penetrate the surface of many entrepreneurial phenomena, offer novel explanations, and make unexpected predictions (Mitchell et al., 2002). For instance, Chowdhury (2005) found that the conventional team diversity variables were not significantly related to new venture performance, but team-level cognitive attributes were. This study similarly shows that the observed prior shared experience effect may actually reflect an underlying team cognitive process. 
Second, this study also contributes to the entrepreneurial cognition literature. Although this literature has made considerable progress during the past decade, most studies have primarily focused on individual-level constructs (Harper, 2008). Recent studies have recognized the importance of adopting team-level cognitive constructs in entrepreneurship studies, but have largely remained as theoretical explorations with few exceptions (Chowdhury, 2005; West, 2007). This study joins this progressive movement by applying a team-level cognitive constructtransactive memory system to reinterpret a previously-discovered effect and demonstrating the explanatory power of team-level cognitive constructs in entrepreneurial settings. This study, together with other studies adopting a team-level cognitive perspective will continuously add valuable constructs to the toolbox of the entrepreneurial cognition literature and advance the entire literature (Baron and Ward, 2004).

This research also extends the transactive memory system theory. The results on intra-team trust reveal that in field studies trust among members could become a crucial factor affecting the utility of transactive memory systems. If members show little trust toward each other, they may be less aware of other members' expertise or disregard information sent from less trustful members. The transactive memory system literature should therefore reconsider the long-held analogy of a transactive memory system as a distributed computer memory which implies a clear-cut distinction between knowing and not knowing the expertise distribution among team members. Transactive memory systems might also have an ambiguous aspect that can be shaped by social factors such as trust or social status (Bunderson, 2003). Additionally, the differences in the moderating effects of task similarity and intra-team trust suggest that transactive memory systems may exhibit complex interactions with team-level factors. Transactive memory system research should reexamine the well-established notion that transactive memory systems are always beneficial and investigate the contingencies surrounding the effects of transactive memory systems (Ren et al., 2006). 
Finally, the practical implications of this research can not be ignored. Entrepreneurs can take at least three lessons from this study. First, prior shared experience was previously viewed as a bundle of multiple factors including transactive memory systems, team cohesion, social identity, etc. This study has worked to tease out at least one important mediating mechanism. The results of this study will enable entrepreneurs to harness the value of prior shared experience by exploiting the transactive memory system advantage. Potential entrepreneurs armed this knowledge should start new ventures with high levels of transactive memory systems, particularly in similar task environments and with high levels of intra-team trust. Second, founding teams without much prior shared experience can emulate the transactive memory system advantage by participating in development techniques (e.g. group training or expertise solicitation). Third, entrepreneurs should reconsider the role of intra-team trust in start-up process. Truthfully, intra-team trust is a desirable element, but over-reliance on intra-team trust without the effective utilization of members' expertise and skills may be counterproductive. This lesson is particularly true for start-ups founded by family members or friends who exhibit high levels of mutual trust, but who may not have a precise understanding of each other's expertise and skills.

\subsection{Limitations and Future Research}

This study can be improved in several ways. First, the cross sectional nature of this study limited the inference power of the findings. Despite careful design of the survey items as well as the temporal separation between prior shared experience and transactive memory systems, it is still likely that the hypothesized link between prior shared experience and transactive memory system can be confounded by other unobserved factors. Future studies adopting a longitudinal design (e.g. repeated experiments or multi-wave surveys) can significantly improve the internal validity of this study (Lewis, 2004). Another concern is that the key findings of this study are drawn from a limited sample of start-ups in China. Future studies can investigate whether or not the proposed 
causal mechanisms hold true or vary for large samples or in other contexts (e.g. the United States). Third, recent studies suggest that transactive memory systems may evolve with membership changes (Lewis et al., 2005), and founding team memberships do change over time (Beckman and Burton, 2008). This study essentially treats membership change as negligible because most sample start-ups experienced few membership changes during their early years. However, a more comprehensive study tracking the evolution of new ventures over a multi-year period should take membership change and its consequences into consideration.

From a broader perspective, it is promising to examine how team cognitive structures affect not only firm performance but also intermediate team behaviors. Future studies can follow the same line of inquiry to explore other interesting topics. For example, how founding teams improvise is an emerging topic in the entrepreneurship literature (Baker and Nelson, 2005). Prior studies have suggested that the pre-founding experience of founders might constitute an important memory that working teams can tap into for improvisation (Moorman and Miner, 1997). Future studies can examine how team-level cognitive structures such as transactive memory systems either enable or disable improvisation within an entrepreneurial context. Research on these topics will definitely enrich our understanding of new venture behaviors and inform new venture performance research. Another promising venue for future studies is to examine the relative impacts of social mechanisms such as intra-team trust, and cognitive mechanisms such as transactive memory systems. This study shows the possibility that cognitive mechanisms might be stronger than social mechanisms. Yet a rigorous research design and careful theorizing are required to make more powerful and accurate inferences.

From a methodological point of view future studies can integrate multiple methods such as simulation and experiments with conventional methods such as multivariate regression. For example, computer simulation can be adopted to precisely capture and model the micro-level 
processes. Particularly relevant to this study, a simulation can better illustrate how transactive memory systems influence team performance as well as how environmental changes moderate the effects of transactive memory systems on team performance (Ren et al., 2006). A plurality of research methods and designs will significantly improve the accuracy of the proposed theories, and enhance our understanding of complex entrepreneurial phenomena.

In conclusion, this study examines the previously discovered prior shared experience effect using a novel team cognition approach. Specifically, this study proposes a transactive memory system framework predicting that the prior shared experience effect is partially mediated by a founding team's transactive memory system. The mediating effect between transactive memory systems and new venture performance is further moderated by two team-level factorstask similarity and intra-team trust. I hope that this study opens the door for future research that can advance this area of study using novel perspectives, particularly a team cognition approach. 


\section{References:}

Global Entrepreneurship Monitor 2008: The China Report.

Agarwal, R., Echambadi, R., Franco, A. M., and Sarkar, M. 2004. Knowledge transfer through inheritance: Spinout generation, development, and survival. Academy of Management Journal, 47(4), 501-522.

Argote, L., McEvily, B., and Reagans, R. 2003. Managing knowledge in organizations: An integrative framework and review of emerging themes. Management Science, 49(4), 571-582.

Austin, J. R. 2003. Transactive memory in organizational groups: The effects of content, consensus, specialization, and accuracy on group performance. Journal of Applied Psychology, 88(5), 866878.

Baker, T. and Nelson, R. E. 2005. Creating something from nothing: Resource construction through entrepreneurial bricolage. Administrative Science Quarterly, 50(3), 329-366.

Bamford, C. E., Dean, T. J., and McDougall, P. P. 2000. An examination of the impact of initial founding conditions and decisions upon the performance of new bank start-ups. Journal of Business Venturing, 15(3), 253-277.

Baron, R. A. and Ward, T. B. 2004. Expanding Entrepreneurial Cognition's Toolbox: Potential Contributions from the Field of Cognitive Science. Entrepreneurship: Theory \& Practice, 28(6), 553-573.

Baron, R. M. and Kenny, D. A. 1986. The moderator-mediator variable distinction in social psychological research: Conceptual, strategic, and statistical considerations. Journal of Personality and Social Psychology, 51(6), 1173-1182.

Beal, D. J., Cohen, R. R., Burke, M. J., and McLendon, C. L. 2003. Cohesion and performance in groups: A meta-analytic clarification of construct relations. Journal of Applied Psychology, 88(6), 989-1004.

Beckman, C. M. 2006. The influence of founding team company affiliations on firm behavior. Academy of Management Journal, 49(4), 741-758.

Beckman, C. M., Burton, D. M., and O'Reilly, C. 2007. Early teams: The impact of team demography on VC financing and going public. Journal of Business Venturing, 22(2), 147-173.

Beckman, C. M. and Burton, D. M. 2008. Founding the future: Path dependence in the evolution of top management teams from founding to IPO. Organization Science, 19(1), 3-24.

Bentler, P. M. 1990. Comparative fit indexes in structural models. Psychological Bulletin, 107(2), 238-246. 
Berman, S. L., Down, J., and Hill, C. W. L. 2002. Tacit knowledge as a source of competitive advantage in the National Basketball Association. Academy of Management Journal, 45(1), 13-31.

Blatt, R. 2009. Tough love: How communal schemas and contracting practices build relational capital in entrepreneurial teams. Academy of Management Review, 34(3), 533-551.

Bliese, P. D. and Halverson, R. R. 1998. Group size and measures of group-level properties: An examination of eta-squared and ICC values. Journal of Management, 24(2), 157-172.

Brandon, D. P. and Hollingshead, A. B. 2004. Transactive memory systems in organizations: Matching tasks, expertise, and people. Organization Science, 15(6), 633-644.

Bunderson, S. J. 2003. Recognizing and utilizing expertise in work groups: A status characteristics perspective. Administrative Science Quarterly, 48(4), 557-591.

Busenitz, L. W. and Barney, J. B. 1997. Differences between entrepreneurs and managers in large organizations: Biases and heuristics in. Journal of Business Venturing, 12(1), 9.

Casciaro, T. and Lobo, M. S. 2008. When competence is irrelevant: The role of interpersonal affect in task-related ties. Administrative Science Quarterly, 53(4), 655-684.

Chandler, G. N. 1996. Business similarity as a moderator of the relationship between preownership experience and venture performance. Entrepreneurship Theory and Practice, 20, 51-65.

Chowdhury, S. 2005. Demographic diversity for building an effective entrepreneurial team: is it important? Journal of Business Venturing, 20(6), 727-746.

Cohen, J., Cohen, P., West, S. G., and Aiken, L. S. 2003. Applied multiple regression/correlation analysis for the behavior sciences. Lawrence Erlbaum Associates, Mahwah, NJ.

Cooper, A. C., Gimeno-Gascon, J. F., and Woo, C. Y. 1994. Initial human and financial capital as predictors of new venture performance. Journal of Business Venturing, 9(5), 371-395.

De Jong, B. A. and Elfring, T. 2010. How does trust affect the performance of ongoing teams? The mediating role of reflexivity, monitoring and effort. Academy of Management Journal, 53(3), 535549.

Delmar, F. and Shane, S. 2006. Does experience matter? The effect of founding team experience on the survival and sales of newly founded ventures. Strategic Organization, 4(3), 215-247.

Dirks, K. T. and Ferrin, D. L. 2001. The role of trust in organizational settings. Organization Science, 12(4), 450-467.

Dutta, D. K. and Thornhill, S. 2008. The evolution of growth intentions: Toward a cognition-based model. Journal of Business Venturing, 23(3), 307-332. 
Edmondson, A. C. 1999. Psychological safety and learning behavior in work teams. Administrative Science Quarterly, 44(2), 350-383.

Eisenhardt, K. M. and Schoonhoven, C. B. 1990. Organizational growth: Linking founding team, strategy, environment, and growth among U.S. semiconductor ventures, 1978-1988.

Administrative Science Quarterly, 35(3), 504-529.

Espinosa, J. A., Slaughter, S. A., Kraut, R. E., and Herbsleb, J. D. 2007. Familiarity, complexity, and team performance in geographically distributed software development. Organization Science, $18(4), 613-630$.

Faraj, S. and Sproull, L. 2000. Coordinating expertise in software development teams.

Management Science, 46(12), 1554-1568.

Foss, N. J. 2010. Why Micro-Foundations for Resource-Based Theory Are Needed and What They May Look Like. Journal of Management, Forthcoming.

Gartner, W. B., Starr, J. A., and Bhat, S. 1999. Predicting new venture survival: An analysis of "Anatomy of a Start-up." Cases from Inc. magazine. Journal of Business Venturing, 14(2), 215-232.

Gibson, C. and Vermeulen, F. 2003. A healthy divide: Subgroups as a stimulus for team learning behavior. Administrative Science Quarterly, 48(2), 202-239.

Gilbert, B. A., McDougall, P. P., and Audretsch, D. B. 2006. New venture growth: A review and extension. Journal of Management, 32(6), 926-950.

Goodman, P. S. and Garber, S. 1988. Absenteeism and accidents in a dangerous environment: Empirical-analysis of underground coal-mines. Journal of Applied Psychology, 73(1), 81-86.

Goodman, P. S. and Leyden, D. P. 1991. Familiarity and group productivity. Journal of Applied Psychology, 76(4), 578-586.

Grégoire, D. A., Corbett, A. C., and McMullen, J. S. 2011. The cognitive perspective in entrepreneurship: An agenda for future research. Journal of Management Studies, 48(6), 14431477.

Grant, R. M. 1996. Toward a knowledge-based theory of the firm. Strategic Management Journal, 17(S1), 109-122.

Gruenfeld, D. H., Mannix, E. A., Williams, K. Y., and Neale, M. A. 1996. Group composition and decision making: How member familiarity and information distribution affect process and performance. Organizational Behavior and Human Decision Processes, 67(1), 1-15.

Harper, D. A. 2008. Towards a theory of entrepreneurial teams. Journal of Business Venturing, 23(6), 613-626. 
Harrison, D. A., Mohammed, S., McGrath, J. E., Florey, A. T., and Vanderstoep, S. W. 2003. Time matters in team performance: Effects of member familiarity, entrainment, and task discontinuity on speed and quality. Personnel Psychology, 56(3), 633-669.

Harrison, D. A. and Klein, K. J. 2007. What's the difference? Diversity constructs as separation, variety, or disparity in organizations. Academy of Management Review, 32(4), 1199-1228.

Haynie, M. J., Shepherd, D., Mosakowski, E., and Earley, C. P. 2010. A situated metacognitive model of the entrepreneurial mindset Journal of Business Venturing, 25(2), 217-229.

Henry, R. A., Strickland, O. J., Yorges, S. L., and Ladd, D. 1996. Helping groups determine their most accurate member: The role of outcome feedback. Journal of Applied Social Psychology, 26(13), 1153-1170.

Hollingshead, A. B. 1998. Communication, learning, and retrieval in transactive memory systems. Journal of Experimental Social Psychology, 34(5), 423-442.

Hoyle, R. H. and Panter, A. T. 1995. Writing about structural equation models. In R. H. Hoyle (Ed.), Structural equation modeling: Concepts, issues, and applications: 158-176. Sage, Thousand Oaks, CA.

James, L. R., Demaree, R. G., and Wolf, G. 1984. Estimating within-group interrater reliability with and without response bias. Journal of Applied Psychology, 69(1), 85-98.

Katz, R. 1982. The effects of group longevity on project communication and performance. Administrative Science Quarterly, 27(1), 81-104.

Khavul, S., Pérez-Nordtvedt, L., and Wood, E. 2010. Organizational entrainment and international new ventures from emerging markets. Journal of Business Venturing, 25(1), 104-119.

Kleinbaum, D. G., Kupper, L. L., Muller, K. E., and Nizam, A. 1988. Applied regression analysis and other multivariate method (2nd ed.). PWS-Kent, Boston, MA.

Klepper, S. 2001. Employee startups in high-tech industries. Industrial and Corporate Change, 10(3), 639-674.

Kogut, B. and Zander, U. 1992. Knowledge of the firm, combinative capabilities, and the replication of technology. Organization Science, 3(3), 383-397.

Kor, Y. Y. 2003. Experience-based top management team competence and sustained growth. Organization Science, 14(6), 707-719.

Lewis, K. 2003. Measuring transactive memory systems in the field: Scale development and validation. Journal of Applied Psychology, 88(4), 587-604.

Lewis, K. 2004. Knowledge and performance in knowledge-worker teams: A longitudinal study of transactive memory systems. Management Science, 50(11), 1519-1533. 
Lewis, K., Lange, D., and Gillis, L. 2005. Transactive memory systems, learning, and learning transfer. Organization Science, 16(6), 581-598.

Liang, W. D., Moreland, R., and Argote, L. 1995. Group versus individual training and group performance: The mediating factor of transactive memory. Personality and Social Psychology Bulletin, 21(4), 384-393.

Littlepage, G., Robison, W., and Reddington, K. 1997. Effects of task experience and group experience on group performance, member ability, and recognition of expertise. Organizational Behavior and Human Decision Processes, 69(2), 133-147.

Lusk, J. and Harrison, K. 2002. The MouseDriver Chronicles. Persus Publishing, Cambridge, MA.

Majchrzak, A., Jarvenpaa, S. L., and Hollingshead, A. B. 2007. Coordinating expertise among emergent groups responding to disasters. Organization Science, 18(1), 147-161.

McEvily, B., Perrone, V., and Zaheer, A. 2003. Trust as an organizing principle. Organization Science, 14(1), 91-103.

Milliken, F. J. 1987. Three types of perceived uncertainty about the environment: State, effect, and response uncertainty. Academy of Management Review, 12(1), 133-143.

Mitchell, R. K., Busenitz, L., Lant, T., McDougall, P. P., Morse, E. A., and Smith, J. B. 2002. Toward a Theory of Entrepreneurial Cognition: Rethinking the People Side of Entrepreneurship Research. Entrepreneurship: Theory \& Practice, 27(2), 93.

Mitchell, R. K., Busenitz, L. W., Bird, B., Marie Gaglio, C., McMullen, J. S., Morse, E. A., and Smith, J. B. 2007. The Central Question in Entrepreneurial Cognition Research 2007. Entrepreneurship: Theory \& Practice, 31(1), 1-27.

Moorman, C. and Miner, A. S. 1997. The impact of organizational memory on new product performance and creativity. Journal of Marketing Research, 34(1), 91-106.

Moreland, R. L. and Myaskovsky, L. 2000. Exploring the performance benefits of group training: Transactive memory or improved communication? Organizational Behavior and Human Decision Processes, 82(1), 117-133.

Moreland, R. L. and Argote, L. 2003. Transactive memory in dynamic organizations. In R. D. Day \& R. S. Peterson \& E. A. Mannix (Eds.), Leading and managing people in the dynamic organization. Lawrence Erlbaum.

Nunnally, J. and Bernstein, I. 1994. Psychometric theory (3rd ed.). McGraw-Hill, New York.

Rau, D. 2005. The influence of relationship conflict and trust on the transactive memory performance relation in top management teams. Small Group Research, 36(6), 746-771. 
Reagans, R., Argote, L., and Brooks, D. 2005. Individual experience and experience working together: Predicting learning rates from knowing who knows what and knowing how to work together. Management Science, 51(6), 869-881.

Ren, Y., Carley, K. M., and Argote, L. 2006. The contingent effects of transactive memory: When is it more beneficial to know what others know? Management Science, 52(5), 671-682.

Roure, J. B. and Maidique, M. A. 1986. Linking prefunding factors and high-technology venture success: An exploratory study. Journal of Business Venturing, 1(3), 295-306.

Schilling, M. A., Vidal, P., Ployhart, R. E., and Marangoni, A. 2003. Learning by doing something else: Variation, relatedness, and the learning curve. Management Science, 49(1), 39-56.

Simons, T. L. and Peterson, R. S. 2000. Task conflict and relationship conflict in top management teams: The pivotal role of intragroup trust. Journal of Applied Psychology, 85(1), 102-111.

Sutcliffe, K. M. and Huber, G. P. 1998. Firm and industry as determinants of executive perceptions of the environment. Strategic Management Journal, 19(8), 793-807.

Tripsas, M. and Gavetti, G. 2000. Capabilities, cognition, and inertia: Evidence from digital imaging. Strategic Management Journal, 21(10-11), 1147-1161.

Walsh, J. P. 1995. Managerial and organizational cognition: Notes from a trip down memory lane. Organization Science, 6(3), 280-321.

Wegner, D. M. 1987. Transactive memory: A contemporary analysis of the group mind. In B. Mullen \& G. R. Goethals (Eds.), Theories of group behavior: 185-208. Springer-Verlag, New York.

West, G. P. 2007. Collective Cognition: When Entrepreneurial Teams, Not Individuals, Make Decisions. Entrepreneurship: Theory \& Practice, 31(1), 77-102.

Yuan, C. Y., Carboni, I., and Ehrlich, K. 2010. The impact of affective relationships and awareness on expertise retrieval: A multilevel network perspective on transactive memory theory. Paper presented at the The Academy of Managment Annual Conference, Montreal, Canada.

Zenger, T. R. and Lawrence, B. S. 1989. Organizational demography: The differential effects of age and tenure distributions on technical communication. Academy of Management Journal, 32(2), 353-376.

Zhang, Z.-X., Hempel, P. S., Han, Y.-L., and Tjosvold, D. 2007. Transactive memory system links work team characteristics and performance. Journal of Applied Psychology, 92(6), 1722-1730.

Zheng, Y., DeVaughn, M. L., and Zellmer-Bruhn, M. 2010. Not all Shared Experience is Equally Beneficial: An Exploration of Founding Team Prior Shared Experience. Working Paper. 
Table 1: Factor Loadings from Confirmatory Factor Analyses

\begin{tabular}{|c|c|c|c|}
\hline \multirow[b]{2}{*}{ Item } & \multicolumn{3}{|c|}{ Factor } \\
\hline & 1 & 2 & 3 \\
\hline \multicolumn{4}{|l|}{ Transactive Memory System (alpha=.86) } \\
\hline \multicolumn{4}{|l|}{ Specialization (alpha $=.79)$} \\
\hline 1. Each founder has specialized knowledge of some aspect about running a start-up. & .57 & & \\
\hline 2. I have knowledge about an aspect of the new venture that no other founder has. & .84 & & \\
\hline 3. Different founders are responsible for expertise in different areas. & .81 & & \\
\hline $\begin{array}{l}\text { 4. The specialized knowledge of several different founders was needed to run the } \\
\text { new venture. }\end{array}$ & .70 & & \\
\hline 5. I know which founders have expertise in specific areas. & .66 & & \\
\hline \multicolumn{4}{|l|}{ Credibility (alpha $=.81)$} \\
\hline 1. I was comfortable accepting procedural suggestions from other founders. & .77 & & \\
\hline $\begin{array}{l}\text { 2. I trusted that other founders' knowledge about running the new venture was } \\
\text { credible. }\end{array}$ & .59 & & \\
\hline $\begin{array}{l}\text { 3. I was confident relying on the information that other founders brought to the } \\
\text { discussion. }\end{array}$ & .84 & & \\
\hline $\begin{array}{l}\text { 4. When other founders provided information, I wanted to double-check it for } \\
\text { myself. (reversed) }\end{array}$ & .76 & & \\
\hline 5. I did not have much faith in other founders' "expertise." (reversed) & .74 & & \\
\hline \multicolumn{4}{|l|}{ Coordination (alpha $=.83)$} \\
\hline 1. Our team worked together in a well-coordinated fashion. & .85 & & \\
\hline 2. Our team had very few misunderstandings about what to do. & .81 & & \\
\hline 3. Our team needed to backtrack and start over a lot. (reversed) & .65 & & \\
\hline 4. We accomplished the task smoothly and efficiently. & .92 & & \\
\hline 5. There was much confusion about how we could accomplish the task. (reversed) & .78 & & \\
\hline \multicolumn{4}{|l|}{ Task Similarity (alpha $=.72)$} \\
\hline $\begin{array}{l}\text { 1. In terms of dealing with customers such as predicting their preferences, the new } \\
\text { venture is similar from my prior working experience. }\end{array}$ & & .71 & \\
\hline $\begin{array}{l}\text { 2. In terms of dealing competitors such as developing competitive strategies, the } \\
\text { new venture is similar from my prior working experience. }\end{array}$ & & .62 & \\
\hline $\begin{array}{l}\text { 3. In terms of financing such as raising capital, the new venture is similar from my } \\
\text { prior working experience. }\end{array}$ & & .59 & \\
\hline $\begin{array}{l}\text { 4. In terms of technology such as manufacturing products, the new venture is } \\
\text { similar from my prior working experience. }\end{array}$ & & .74 & \\
\hline $\begin{array}{l}\text { 5. In terms of human resources issues such as recruiting and promoting, the new } \\
\text { venture is similar from my prior working experience. }\end{array}$ & & .53 & \\
\hline \multicolumn{4}{|l|}{ Intra-Team Trust (alpha $=.91)$} \\
\hline $\begin{array}{l}\text { 1. I am confident that my team members will take my interests into account when } \\
\text { making work-related decisions. }\end{array}$ & & & .86 \\
\hline $\begin{array}{l}\text { 2. I am confident that that my team members will keep me informed about issues } \\
\text { that concern my work. }\end{array}$ & & & .81 \\
\hline $\begin{array}{l}\text { 3. I am able to count on my team members for help if I have difficulties with my } \\
\text { job. }\end{array}$ & & & .80 \\
\hline 4. I am not certain that my team members trust me (reversed). & & & .75 \\
\hline 5. In general, I believe my team members' motives and intentions are benevolent. & & & .82 \\
\hline
\end{tabular}


Table 2: Descriptive Statistics and Correlation Matrix

\begin{tabular}{|c|c|c|c|c|c|c|c|c|c|c|c|c|c|c|}
\hline ID & Variables & Mean & S.D. & 1 & 2 & 3 & 4 & 5 & 6 & 7 & 8 & 9 & 10 & 11 \\
\hline 1 & New Venture Growth & 3.27 & 1.09 & & & & & & & & & & & \\
\hline 2 & Age Diversity & 3.65 & 1.17 & -.12 & & & & & & & & & & \\
\hline 3 & Gender Diversity & .30 & .46 & -.03 & -.22 & & & & & & & & & \\
\hline 4 & Education Diversity & .11 & .31 & -.15 & .14 & -.08 & & & & & & & & \\
\hline 5 & Ethnic Minority & .74 & .44 & .02 & -.08 & .01 & -.28 & & & & & & & \\
\hline 6 & Total Working Experience (Logged) & 3.61 & 1.94 & .11 & .06 & .07 & .12 & .08 & & & & & & \\
\hline 7 & Prior Founding Experience & .19 & .39 & .08 & .06 & -.23 & .13 & -.09 & -.06 & & & & & \\
\hline 8 & Ongoing Shared Experience & 26.89 & 6.97 & .18 & -.05 & -.04 & .02 & -.07 & .10 & .01 & & & & \\
\hline 9 & Prior Shared Experience & .27 & .45 & .11 & .24 & -.08 & .10 & -.05 & .07 & .18 & .03 & & & \\
\hline 10 & Transactive Memory System & 3.45 & .53 & .26 & -.02 & -.12 & -.23 & .18 & .01 & -.04 & .12 & .37 & & \\
\hline 11 & Task Similarity & 4.03 & .96 & .23 & -.17 & .07 & -.06 & .11 & .18 & -.13 & .05 & .18 & .25 & \\
\hline 12 & Intra-team Trust & 3.48 & .79 & .10 & .05 & .10 & -.14 & .07 & -.03 & -.04 & -.04 & .24 & .19 & .12 \\
\hline
\end{tabular}

$\mathrm{N}=98$, correlation coefficients greater than $|.20|$ are significant at .05 level. 
Table 3: Ordinary Least Squares Estimation of New Venture Growth

\begin{tabular}{|c|c|c|c|c|c|c|}
\hline Variables & Model 1 & Model 2 & Model 3 & Model 4 & Model 5 & Model 6 \\
\hline Regional Dummies & Included & Included & Included & Included & Included & Included \\
\hline Age Diversity & $\begin{array}{l}-.08 \\
(.11)\end{array}$ & $\begin{array}{l}-.09 \\
(.12)\end{array}$ & $\begin{array}{l}-.08 \\
(.13)\end{array}$ & $\begin{array}{l}-.08 \\
(.12)\end{array}$ & $\begin{array}{l}-.02 \\
(.13)\end{array}$ & $\begin{array}{l}-.04 \\
(.12)\end{array}$ \\
\hline Gender Diversity & $\begin{array}{r}.18 \\
(.25)\end{array}$ & $\begin{array}{l}.21 \\
(.26)\end{array}$ & $\begin{array}{r}.23 \\
(.27)\end{array}$ & $\begin{array}{r}.27 \\
(.28)\end{array}$ & $\begin{array}{l}.26 \\
(.27)\end{array}$ & $\begin{array}{l}.26 \\
(.29)\end{array}$ \\
\hline Education Diversity & $\begin{array}{r}-1.02 \\
(.73)\end{array}$ & $\begin{array}{r}-1.08 \\
(.69)\end{array}$ & $\begin{array}{r}-1.41+ \\
(.78)\end{array}$ & $\begin{array}{l}-1.48 \\
(1.07)\end{array}$ & $\begin{array}{r}-1.45+ \\
(.81)\end{array}$ & $\begin{array}{l}-1.49 \\
(.1 .08)\end{array}$ \\
\hline Ethnic Minority & $\begin{array}{r}.81 \\
(.65)\end{array}$ & $\begin{array}{r}.82 \\
(.66)\end{array}$ & $\begin{array}{r}.92 \\
(.68)\end{array}$ & $\begin{array}{r}.89 \\
(.69)\end{array}$ & $\begin{array}{r}.85 \\
(.68)\end{array}$ & $\begin{array}{r}.87 \\
(.60)\end{array}$ \\
\hline $\begin{array}{l}\text { Total Working Experience } \\
\text { (Logged) }\end{array}$ & $\begin{array}{l}.36^{*} \\
(.19)\end{array}$ & $\begin{array}{l}.38+ \\
(.21)\end{array}$ & $\begin{array}{l}.46+ \\
(.25)\end{array}$ & $\begin{array}{r}.41 \\
(.27)\end{array}$ & $\begin{array}{l}.45+ \\
(.24)\end{array}$ & $\begin{array}{r}.40 \\
(.29)\end{array}$ \\
\hline Prior Founding Experience & $\begin{array}{r}.05 \\
(.05)\end{array}$ & $\begin{array}{l}.04 \\
(.06)\end{array}$ & $\begin{array}{r}.03 \\
(.07)\end{array}$ & $\begin{array}{r}.03 \\
(.06)\end{array}$ & $\begin{array}{l}-.02 \\
(.07)\end{array}$ & $\begin{array}{r}.03 \\
(.08)\end{array}$ \\
\hline Ongoing Shared Experience & $\begin{array}{l}.16^{*} \\
(.08)\end{array}$ & $\begin{array}{l}.15+ \\
(.09)\end{array}$ & $\begin{array}{r}.13 \\
(.10)\end{array}$ & $\begin{array}{r}.14+ \\
(.08)\end{array}$ & $\begin{array}{l}.13 \\
(.10)\end{array}$ & $\begin{array}{r}.13 \\
(.11)\end{array}$ \\
\hline Prior Shared Experience & $\begin{array}{l}.53 * \\
(.22)\end{array}$ & $\begin{array}{l}.40+ \\
(.21)\end{array}$ & $\begin{array}{r}.36 \\
(.26)\end{array}$ & $\begin{array}{r}.31 \\
(.25)\end{array}$ & $\begin{array}{r}.33 \\
(.26)\end{array}$ & $\begin{array}{r}.29 \\
(.25)\end{array}$ \\
\hline Transactive Memory System & & $\begin{array}{l}.42 * \\
(.19)\end{array}$ & $\begin{array}{l}.40^{*} \\
(.20)\end{array}$ & $\begin{array}{r}.32+ \\
(.18)\end{array}$ & $\begin{array}{l}.35 \\
(.29)\end{array}$ & $\begin{array}{l}.38+ \\
(.20)\end{array}$ \\
\hline Task Similarity & & & $\begin{array}{l}.24+ \\
(.14)\end{array}$ & $\begin{array}{l}-.61 \\
(.35)\end{array}$ & $\begin{array}{l}.31+ \\
(.17)\end{array}$ & $\begin{array}{r}-.65+ \\
(.36)\end{array}$ \\
\hline Intra-Team Trust & & & $\begin{array}{l}.13 \\
(.12)\end{array}$ & $\begin{array}{l}.15 \\
(.13)\end{array}$ & $\begin{array}{l}.54+ \\
(.28)\end{array}$ & $\begin{array}{l}.51 \\
(.30)\end{array}$ \\
\hline $\begin{array}{l}\text { Transactive Memory System } \\
\text { *Task Similarity }\end{array}$ & & & & $\begin{array}{l}.34+ \\
(.19)\end{array}$ & & $\begin{array}{l}.33+ \\
(.19)\end{array}$ \\
\hline $\begin{array}{l}\text { Transactive Memory System } \\
\text { *Intra-Team Trust }\end{array}$ & & & & & $\begin{array}{l}.34 * \\
(.18)\end{array}$ & $\begin{array}{l}.32+ \\
(.17)\end{array}$ \\
\hline Observations & 98 & 98 & 98 & 98 & 98 & 98 \\
\hline R-squared & .16 & .19 & .21 & .23 & .25 & .26 \\
\hline
\end{tabular}

Standard errors in parentheses, ${ }^{*} * \mathrm{p}<.01,{ }^{*} \mathrm{p}<.05$ and $+\mathrm{p}<.1$ (two-tailed tests) 
Figure 1: Conceptual Framework

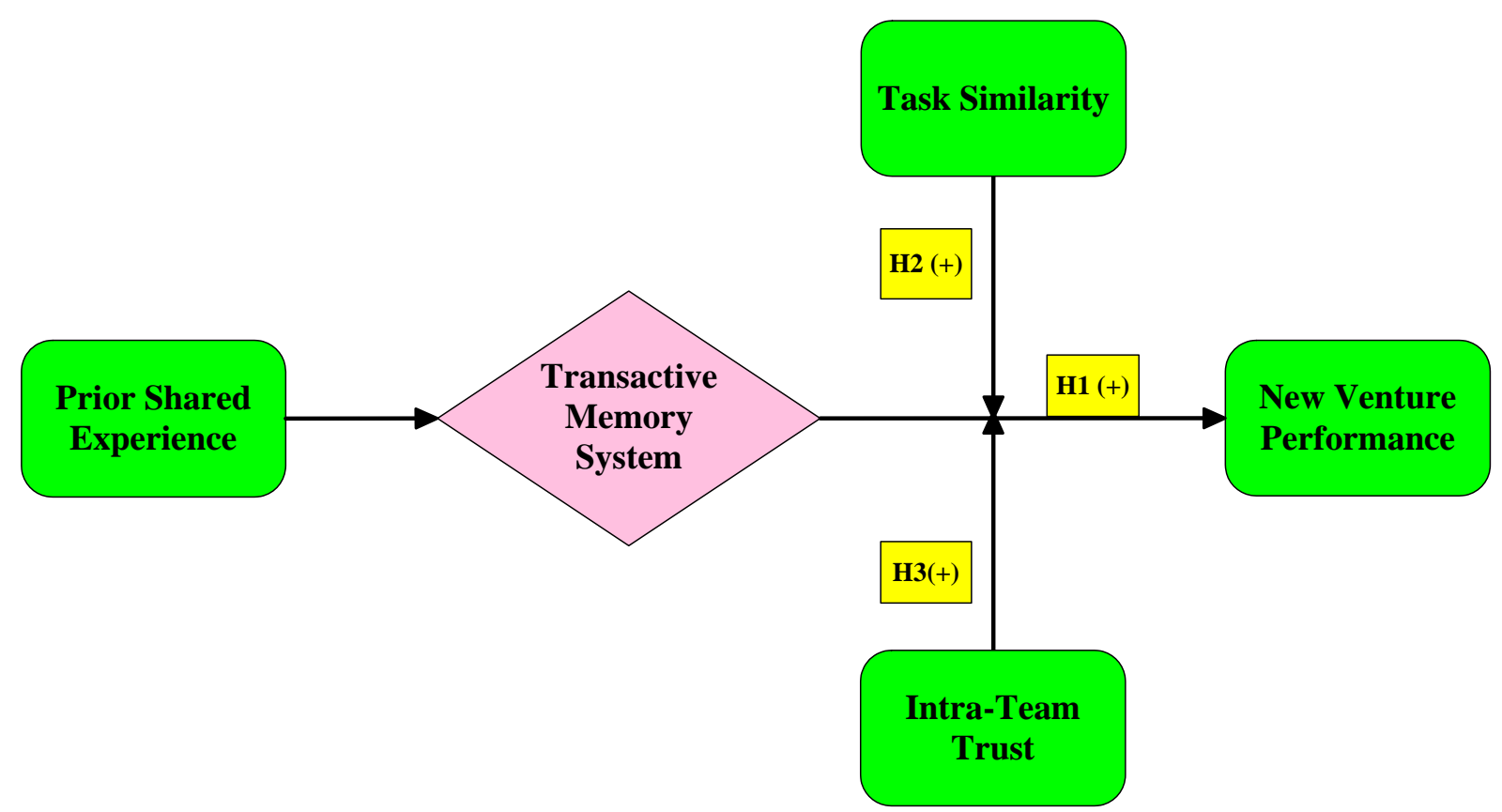


Figure 2: Interaction Plots

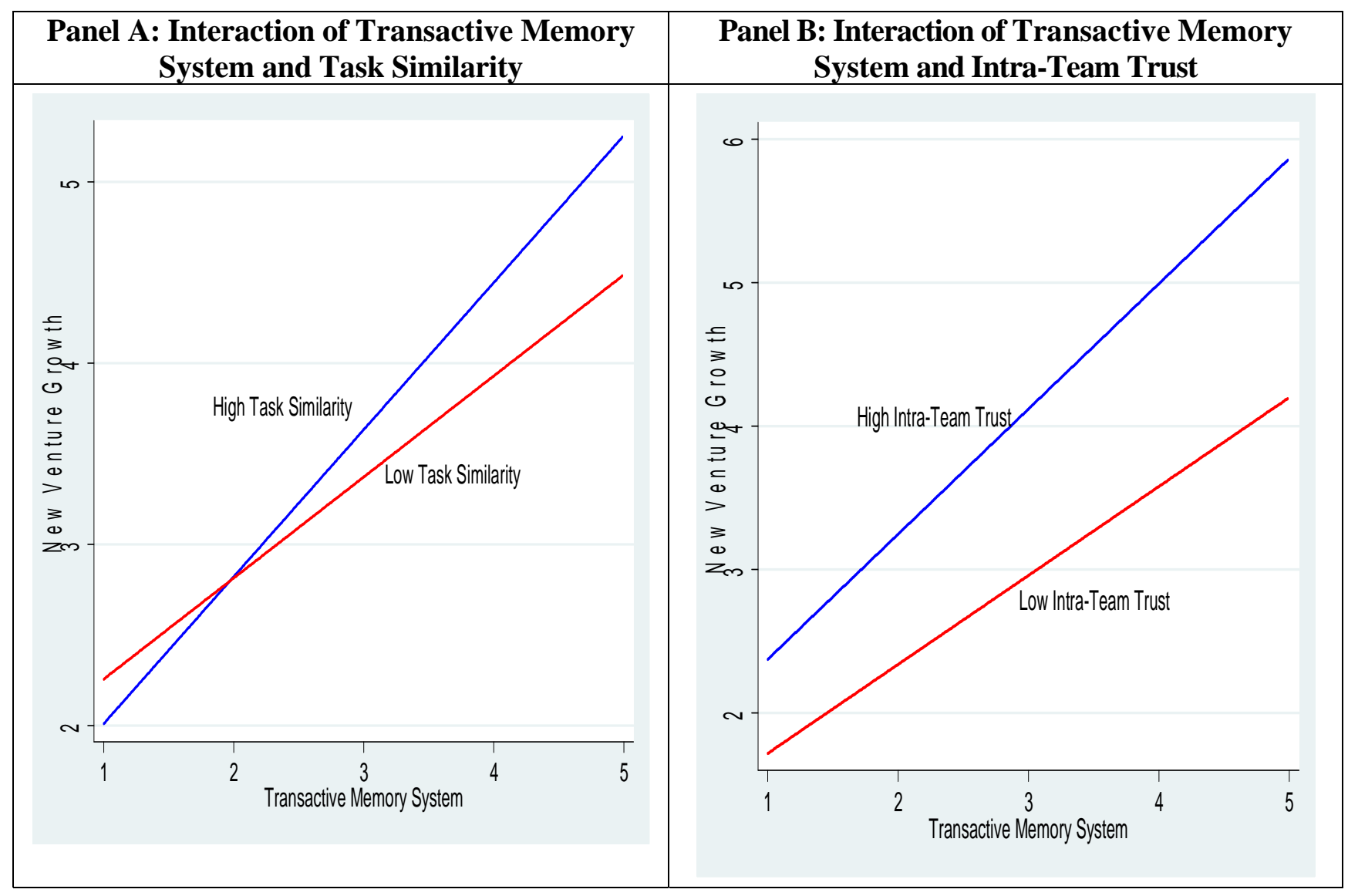

